
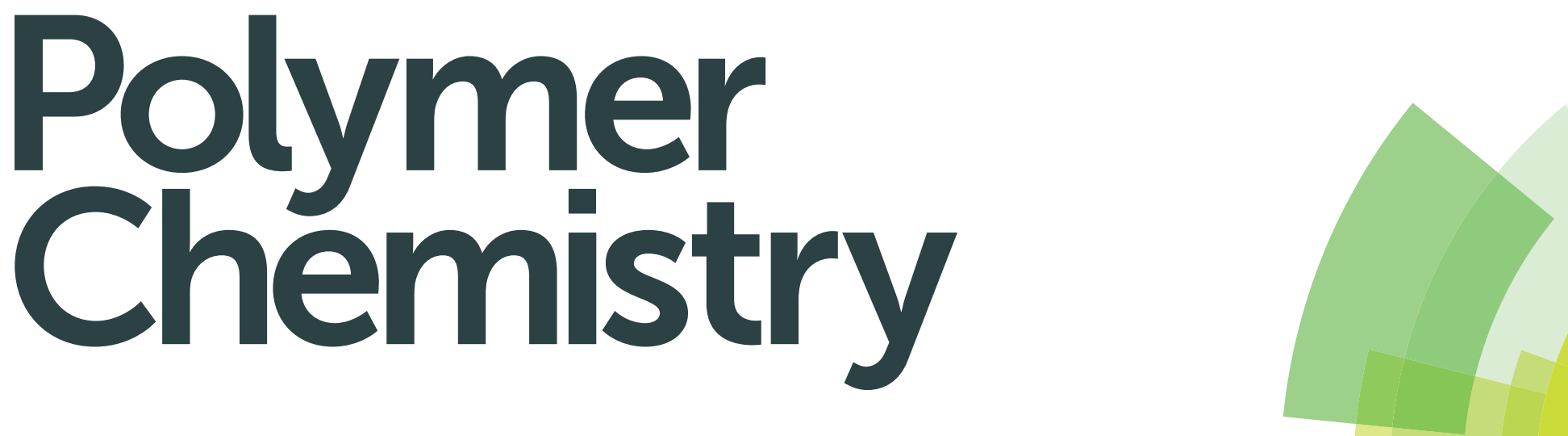

www.rsc.org/polymers

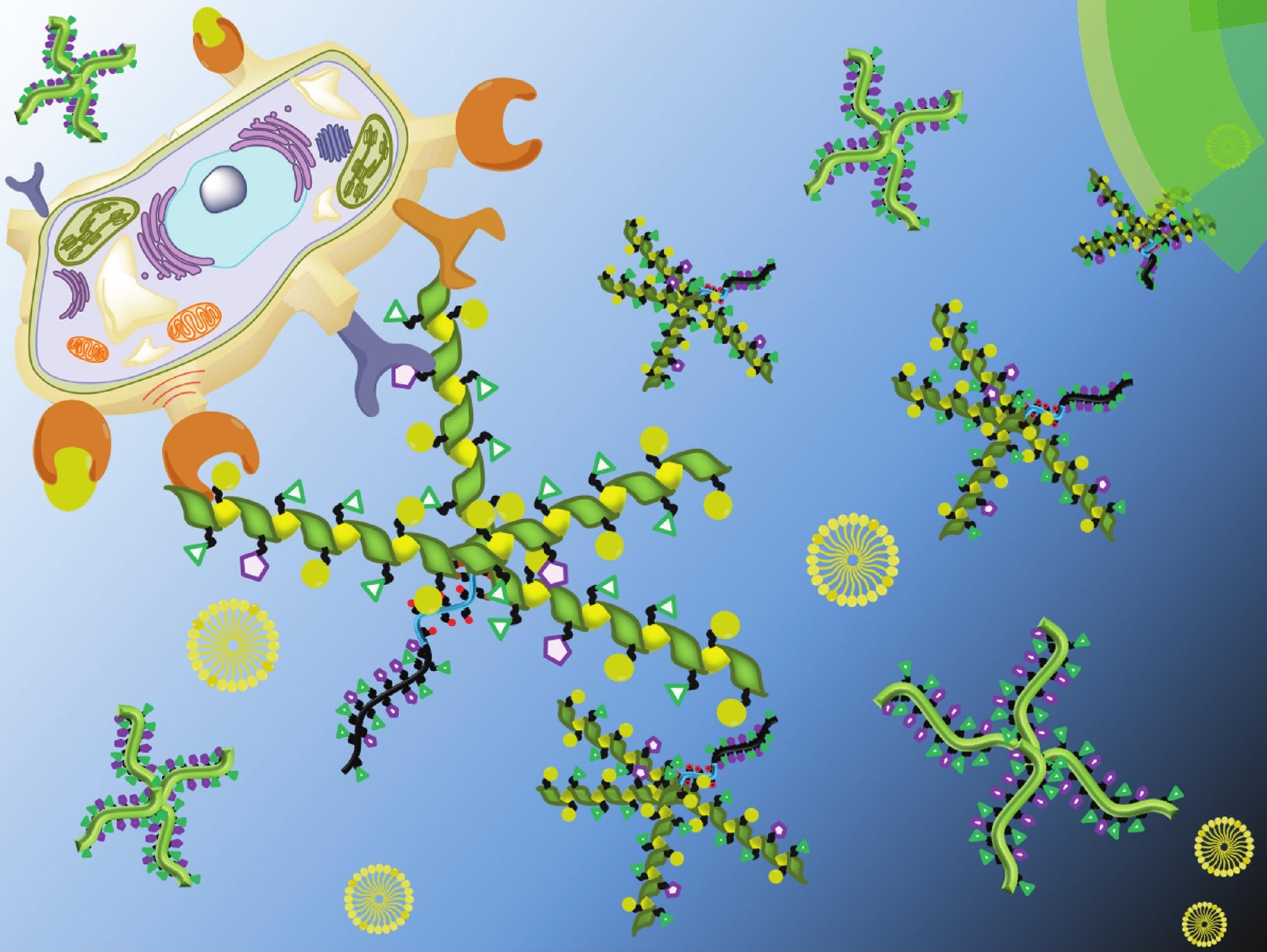

ISSN 1759-9954

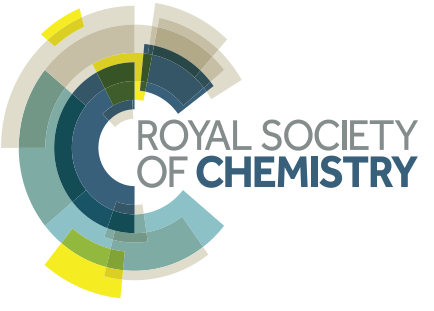




\section{Glyconanoparticles and their interactions with lectins}

Cite this: Polym. Chem., 2015, 6, 5503

Received 21st January 2015, Accepted 26th February 2015 DOI: $10.1039 / \mathrm{c} 5$ py00089k www.rsc.org/polymers

\author{
Gokhan Yilmaz ${ }^{\mathrm{a}, \mathrm{b}}$ and C. Remzi Becer*c
}

Recent progress in nanobiotechnology has allowed the use of glycans and their conjugates as biofunctional molecules for many biological and biomedical applications. Therefore, specific interactions of carbohydrate-binding proteins (lectins) are continuously being elucidated for a deep understanding of their functions and the precise mechanism of their association with specific ligands. New generations of glyconanoparticles with outstanding features that present carbohydrates in a multivalent manner and locally in high concentrations have been showing promise of establishing the glycan code and functioning as a glycan mimic. In the first part of this review article, different types of lectins have been summarised and their main properties highlighted. In the second part, recent successful examples of glyconanoparticles formed of synthetic polymers and in most cases, conjugated with metals, have been discussed in terms of their synthesis and interactions with lectins.

\section{Introduction}

During the last decade, there has been a great deal of interest in the integration of nanotechnology with carbohydrates. The advances in glyconanotechnology have allowed the creation of different bioactive glyconanostructures for various health related applications such as drug delivery, biomaterials, gene

${ }^{a}$ Department of Chemistry, University of Warwick, CV4 7AL Coventry, UK

${ }^{b}$ Department of Basic Sciences, Turkish Military Academy, 06654 Ankara, Turkey ${ }^{c}$ School of Engineering and Materials Science, Queen Mary, University of London, Mile End Road, E1 4NS London, UK.E-mail: r.becer@qmul.ac.uk therapy, pathogen detection, inhibitors of toxins and lectinbased biosensors. ${ }^{1-6}$ Nanoparticles functionalized with carbohydrates presented a highly multivalent method of interaction with lectins and allowed the preparation of high local concentrations of ligands on a small surface. The insertion of their biological properties into nanostructured materials has attracted much attention to carbohydrates due to their use in bio-mimetic purposes, crucial role in bio-recognition processes at the molecular level and functional role in living systems. ${ }^{7,8}$ Their major function is to serve as recognition markers. ${ }^{9}$ Although the binding between carbohydrates and lectins is weak, it could be greatly enhanced by the multivalent effect of

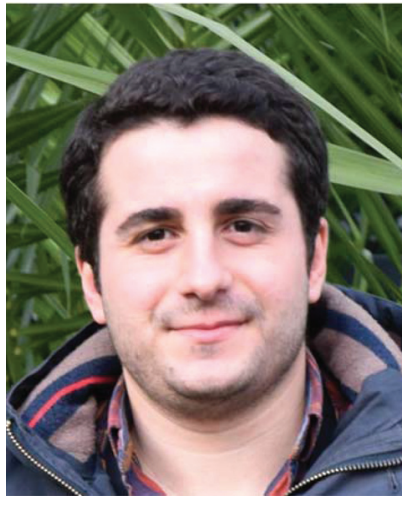

Gokhan Yilmaz
Gokhan Yilmaz received his Chemical Engineering diploma from Hacettepe University, Turkey, in 2010. He is currently a PhD student at the University of Warwick and Queen Mary University of London under the supervision of Dr Remzi Becer. The Turkish Armed Forces has awarded him with a full scholarship for his PhD study. His research project is focused on the synthesis of precision glycopolymers and investigations on their binding affinity through different types of lectins for various biological applications. He is also interested in the preparation of glyconanoparticles using different synthesis techniques in order to improve their utility in biomedicine and materials science.

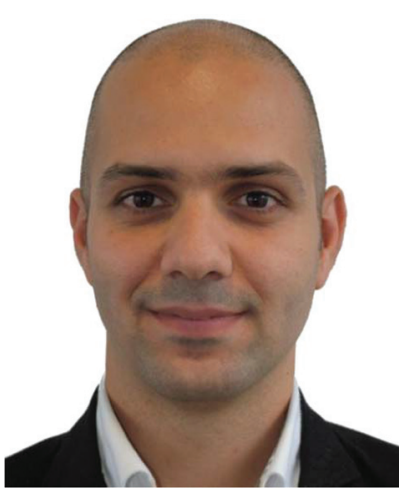

C. Remzi Becer
Remzi Becer received his BSc and $\mathrm{MSc}$ degrees in chemistry at Istanbul Technical University. He completed his PhD in 2009 under the guidance of Prof. Ulrich Schubert at Eindhoven University of Technology. He received a Marie Curie IntraEuropean Fellowship in 2009 and joined the group of Prof. David Haddleton, University of Warwick. He was awarded a Science City Interdisciplinary Senior Research Fellowship in 2011 to start up his independent research group at the University of Warwick. In 2013, he was appointed as a Senior Lecturer in the School of Engineering and Materials Science at Queen Mary University of London. 

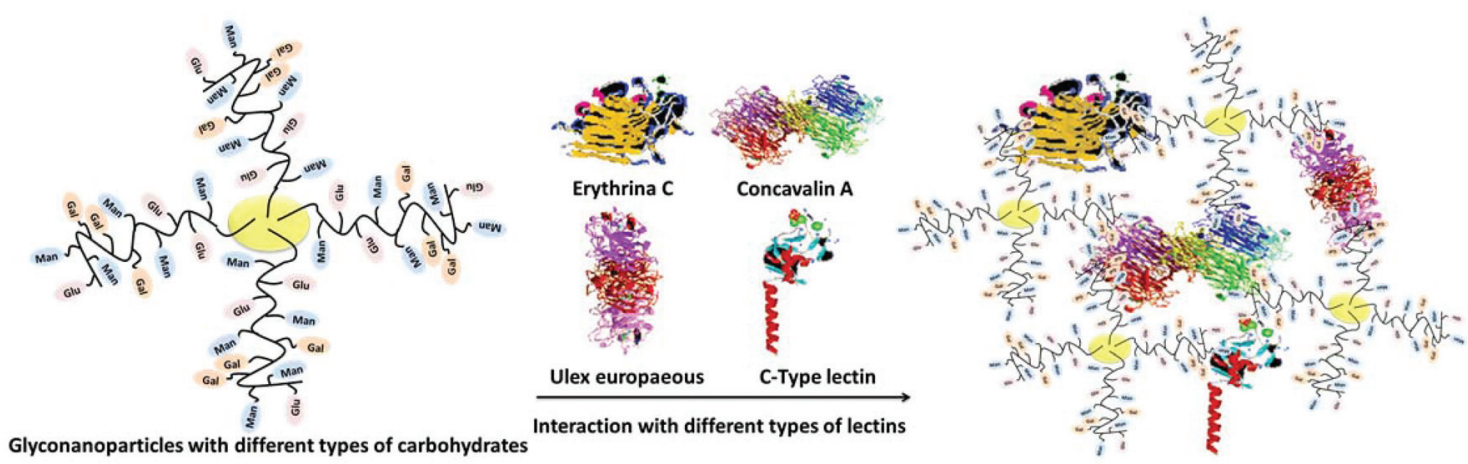

Fig. 1 Schematic representation of metallic nanoparticles with different types of carbohydrates and their interaction with different types of lectins.

densely packed carbohydrate molecules with unique functionalities, which is known as the "glycocluster effect". ${ }^{10,11}$ Glyconanoparticles as carbohydrate-based systems function in a similar manner to mimic the behavior of naturally existing glycocalyx. Therefore, the fabrication and engineering of highly innovative glyconanoparticles with unique physiochemical properties help to further enhance their specific recognition properties on multivalent scaffolds in glycoscience.

Glycopolymers are synthetic macromolecules with sugar moieties and have a great potential for mimicking the oligosaccharides. ${ }^{12-15}$ Oligosaccharides play a key role in many biological processes such as signal transmission, intercellular recognition and fertilization. ${ }^{16-19}$ Self-assembled/decided nano-objects and scaffolds functionalized with oligosaccharides were designed to study and evaluate carbohydrate-carbohydrate and carbohydrate-protein interactions. ${ }^{20,21}$ The conjugation of glycopolymers with biomolecules such as proteins, oligopeptides, deoxyribonucleic acid plasmids, lipids, phospholipids, and ligands was performed to yield a large family of neoglycoconjugates with desirable properties for the construction of self-assembled glyconanoparticles (Fig. 1).

Moreover, glycopolymer nanocarriers have been prepared in different forms including vesicles, micelles, nanoparticles and nanofibers, for the delivery of bioactive molecules, such as folic acid, biotin-avidin, antibodies and DNA sequences. According to recent developments in the routine synthetic methods of complex glycoconjugates, it is nowadays possible to design new polyvalent systems providing multivalent carbohydrate-receptor interactions. Basically, there are several types of glyconanoparticles, namely, metallic, semiconductor glycoquantum dots, magnetic and self-assembled glyconanoparticles. In this context, recent advanced and selected metallic and polymeric glyconanoparticles showing specific interactions with various lectins are highlighted, but first typical lectins utilized in glyconanoparticle interactions are summarized.

\section{Lectins}

Lectins (latin: legere (to select)) that were described at the end of the $19^{\text {th }}$ century are defined as carbohydrate-binding proteins. ${ }^{22}$ Lectins are fundamental to many important biological processes and living organisms. ${ }^{23,24}$ They are ubiquitously spread in nature and are also major components of the outer surface of mammalian cells. Lectins have a specific and reversible interaction with carbohydrates non-covalently, known as cell agglutination. Furthermore, many bacteria have the ability to agglutinate erythrocytes by its lectins. The major attribute of the activity of lectins is obtained by using the agglutination and precipitation processes. There are a wide variety of lectins in terms of their different structures and sizes. Sharon and co-workers pioneered the study of the binding between lectins and carbohydrates and also did a classification based on the monosaccharide ligand toward which they exhibit the highest affinity. ${ }^{23}$ This classification is losing its utility slowly due to marked differences in the fine specificities of lectins within a single category. Moreover, several different types of lectins that have now been isolated from organisms such as plants, animals and microorganisms do not show sufficient binding affinity toward simple saccharides. There is another way to make a classification according to their molecular structure. The first group named simple lectins consists of a small number of subunits with molecular weights typically below $40 \mathrm{kDa}$. The second, consist of mosaic lectins which are very diverse in structure, from different sources: viral hemagglutinins, animal lectins of C-, P- and I-types consist of different types of protein domains. The last group consists of macromolecular assembly lectins, which are filamentous and heteropolymeric organelles. They commonly exist in bacteria. However, their structure has a minor component site for interaction with carbohydrate.

Bacterial adhesion, which is an important mechanism for the attachment of bacteria onto cells, is based on molecular interactions between cell surface carbohydrates of the host and specialised carbohydrate-specific bacterial lectins. ${ }^{25}$ This adhesion process has to be accomplished by bacteria for the arrangement onto cell surfaces of the host because of withstanding natural defence mechanisms and mechanical shear stress. Stable adhesion can lead to the formation of bacterial biofilms, which is accompanied by vital advantages for the microbial colonies but disadvantages for the host. Fimbriae 


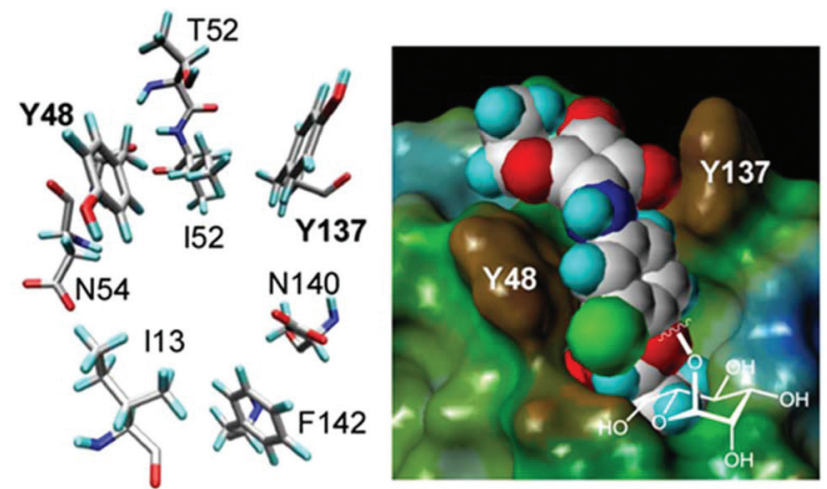

Fig. 2 Spatial orientation of the amino acid residues at the entrance of the carbohydrate binding site of the bacterial lectin $\mathrm{FimH}$ as revealed by crystallography (left). Fit of top scoring conformations of designed mannoside ligands. The FimH carbohydrate binding site depicted as the Connolly surface and complexed with the squaric acid derivative of $\alpha$-Dmannoside (right). Reproduced with permission from Royal Society of Chemistry. ${ }^{26}$

are particularly efficient adhesion tools of bacteria to mediate colonization of various biotic and abiotic surfaces.

Fimbriae are a hair-like lectin that is present on bacteria. Fimbriae-mediated bacterial adhesion is so important because $\alpha$-D-mannosides with an aromatic aglycone moiety exhibit an improved affinity to the bacterial lectin and an enhanced potency as inhibitors of type 1 fimbriae-mediated bacterial adhesion to surfaces. As depicted in Fig. 2, the carbohydratebinding site of FimH (type 1 fimbrial lectin) has a specific interaction with two tyrosine residues (Y48 and Y137) due to $\pi-\pi$ interactions with an aromatic aglycone of an $\alpha$-D-mannoside ligand. ${ }^{26}$

\subsection{Plant lectins}

Plant lectins are used very commonly for the examination of the multivalent binding of carbohydrates. Even though many different biological functions of lectins in plants have still not been investigated in great detail, it is known that they play important roles in the external and internal biological activities of plants such as protection of the plant from fungal attack and herbivorous animals, storage of proteins, modulation of enzymatic activities, and adjustment to altered environmental conditions. ${ }^{27}$ Legume lectins are the biggest family and the most well-studied among basic plant lectins. More than 100 lectins have been isolated and characterized structurally from the seeds of the plants in which they are present. Concanavalin A (Con A) has been the first member of this family since its discovery in $1919 .{ }^{28}$ Con A is the most popular and low-cost plant lectin as well as having high binding affinity with mannose and glucose. Therefore, it is usually used as a model lectin to investigate the multivalent binding of glycopolymers. Con A was originally extracted and isolated from the Jack bean and its molecular weight is around 104-112 kDa. As in C-type lectins, Con A binds metallic atoms
$\left(\mathrm{Mn}^{2+}\right.$ and $\left.\mathrm{Ca}^{2+}\right)$ and also these cations enhance significantly the binding ability of Con A with carbohydrates. Moreover, Con A is a tetramer at neutral $\mathrm{pH}$ with four subunits in a tetrahedral orientation where the binding sites are $72 \AA$ apart from each other.

Peanut agglutinin (PNA) is another legume that binds to galactose, preferably to galactosyl $(\beta, 1-3) \mathrm{N}$-acetylgalactosamine, and has a wide range of applications. ${ }^{29}$ PNA shows an unusual "open" quaternary structure, where the homotetramer possesses neither $222\left(D_{2}\right)$ nor 4 -fold $\left(C_{4}\right)$ symmetry. ${ }^{29}$ This structure can be stabilised mainly by hydrophobic, hydrogenbonded and water-mediated interactions. Moreover, a partially unfolded intermediate of PNA retains carbohydrate binding ability with affinities that are $75-85 \%$ of those of native PNA. ${ }^{29}$ Although not always directly necessary for binding, the divalent cations help their carbohydrate binding. Triticum vulgare (wheat germ agglutinin, WGA) belongs to the Gramineae family and is a dimeric lectin with eight binding sites for GlcNAc that are separated by distances of $14 \AA^{30}{ }^{30}$ It exists in three isoforms, WGA1, WGA2 and WGA3 with a high specificity to $N$-acetylglucosamine and $N$-acetylneuraminic acid. WGA has the ability to recognise specifically the pathogen for plant defence mechanisms. Ricinus communis (ricin) is isolated from castor bean and binds selectively to galactose. ${ }^{31}$ Ricin is a ribosome-inactivating protein and is also used for generating immunotoxins. The two lectins, ricin and Ricinus communis agglutinin (RCA) are closely related, are among the most toxic lectins and can cause rapid death. ${ }^{32}$ Jacalin from the Moraceae family that is extracted from the Jackfruit (Artocarpus integrifolia) can recognize galactose $(\beta, 1-3) N$-acetylgalactosamine and immunoglobulin A (IgA).

\subsection{Animal lectins}

Animal lectins were originally listed in 12 families, which are C-, I-, P, S-type lectins, pentraxins, trout lectins, discoidins, calnexin and calreticulin, ERGIC-53 and VIP-36, fucolectins, annexin lectins and fibrinogen-type lectins. ${ }^{33}$ Despite increased knowledge about their structures and functionalities, animal lectins are still more complicated in comparison with plant lectins. C-type lectins are the most commonly used animal lectins that need $\mathrm{Ca}^{2+}$ ions for binding with carbohydrates. The large family of C-type lectins includes collectins, selectins, endocytic receptors, and proteoglycans. ${ }^{34}$ They differ significantly in the types of glycans that they recognize with high affinities due to their carbohydrate-recognition domains. C-type lectins serve many different functions in animals, such as cell-cell adhesion, immune response to pathogens, the control of protein levels in the blood and apoptosis. Proteins use the C-type lectin fold to bind other proteins, lipids, and inorganic molecules. C-type lectins can have a variable number of subunits with 1-8 binding sites per subunit. The C-type lectin folding is unique and has a compact domain of 110-130 amino acid residues with a double-looped, two-stranded antiparallel $\beta$-sheet formed by the amino-and carboxy-terminal residues connected by two $\alpha$-helices and a three-stranded antiparallel $\beta$-sheet. As depicted in Fig. $3, \mathrm{Ca}^{2+}$ cations in the 


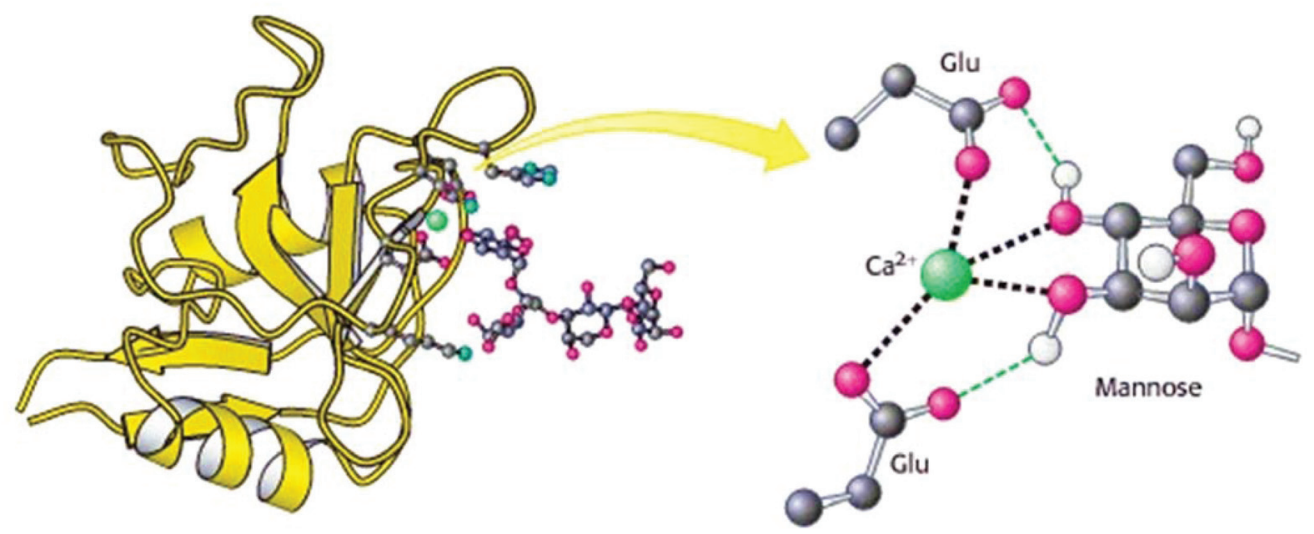

Fig. 3 Structure of a C-type carbohydrate-binding domain from an animal lectin. Reproduced with permission from W. H. Freeman and Company, Copyright 2002. ${ }^{34}$

carbohydrate-recognition domains often coordinated to amino acid residues with carbonyl side chains and these residues directly bind to sugars when $\mathrm{Ca}^{2+}$ is bound in site 2 .

C-type lectins are the endocytic lectins acting as the hepatic galactose $/ N$-acetylglucosamine receptor. Moreover, many C-type lectins exist as trimers, including the trimeric rat mannosebinding protein-A in complex with $\alpha$-methyl mannoside. Interestingly, some C-type lectins are extremely small, e.g. hepatic intestinal pancreatic protein and pancreatic stone protein. ${ }^{35}$ Selectins are the best characterized family of C-type lectins in terms of their extensively documented roles as cell-adhesion molecules. ${ }^{35}$ Specific interaction between the selectins and cellsurface glycoconjugate ligands plays a key role in adhesive interactions among these cells. Selectins are classified into four subtypes: E-selectin (in endothelial cells), PSGL-1-selectin (in hematopoietic cells), L-selectin (in leukocytes) and P-selectin (in platelets and endothelial cells). They show a specific affinity to mannose, but also to fucose and $\mathrm{N}$-acetylglucosamine.

I-type lectins are from the immunoglobulin superfamily, excluding antibodies and T-cell receptors. The Siglec family of sialic acid-binding lectins is the only well-characterized group of I-type lectins regarding both structure and function. ${ }^{36}$ P-type lectins play an important role in the generation of functional lysosomes within the cells of higher eukaryotes by directing newly synthesized lysosomal enzymes bearing the mannose 6-phosphate signal to lysosomes. ${ }^{37}$ The only two members of the P-type lectin family, the cation-dependent mannose 6-phosphate receptor and the insulin-like growth factor II/mannose 6-phosphate receptor, have the great ability to recognize phosphorylated mannose residues.

Pentraxins that are a family of evolutionarily conserved pattern-recognition proteins are divided into two groups: short pentraxins and long pentraxins. ${ }^{38}$ The two short pentraxins are C-reactive protein (CRP) and serum amyloid P-component (SAP). The prototype protein of the long pentraxin group is pentraxin 3 (PTX3). CRP and SAP are produced primarily in the liver while PTX3 is produced in a variety of tissues during inflammation. ${ }^{39}$ The short pentraxins perform several functions to recognize a variety of pathogenic agents and then to either eliminate them or neutralize their harmful effects by utilizing the complement pathways and macrophages in the host. CRP has specific interaction with small nuclear ribonucleoproteins while SAP has the ability to recognize DNA, and two nuclear autoantigens. CRP participates in the resolution of cardiovascular, infectious, and autoimmune diseases. However, SAP recognizes carbohydrates, nuclear substances, and amyloid fibrils and thus participates in the resolution of infectious diseases, autoimmunity, and amyloidosis. PTX3 can interact with several ligands, including growth factors, the extracellular matrix component and selected pathogens, playing a role in complement activation and facilitating pathogen recognition by phagocytes.

Galectin was first discovered in 1976 and was isolated from a chick muscle. ${ }^{40}$ After its purification, the calf heart/lung galectin is approximately $15 \mathrm{kDa}$ in size and occurs as a noncovalent dimer. Many galectins have now been identified in animals based on the conserved galectin carbohydrate-recognition domains. Generally, galectins have binding ability with $\beta$-galactosides, preferably as lactose and $N$-acetyl lactosamine, and a significant sequence similarity in the carbohydratebinding site. Galectins can contribute to cell-cell and cellmatrix interactions and regulate immune and inflammatory responses. Some galectins have shown their importance and necessity in cancer progression.

\section{Glyconanoparticles}

\subsection{Metallic glyconanoparticles}

A metallic core (noble metals, magnetic elements, semiconductors) can be functionalized with different types of glycopolymers to make a carbohydrate shell. Conjugation of sugar derivatives onto these metal-based nanoclusters presents interesting properties which include a wide array of assembling models and size-related electronic, magnetic and optical properties. Moreover, metallic glyconanoparticles (GNPs) have opened avenues to develop the carbohydrate-based multivalent 
systems due to their easy modification in size and composition. In this way, multifunctional behaviour can be directly inserted into the organic shell. The interaction with suitable functionalized biological ligands onto metallic GNPs can offer an important contribution for the development of diagnostic tools and innovative therapies. GNPs can create a glycocalyxlike shell with a globular shape and chemically defined composition to understand better the main functions of the carbohydrates at the cell surface.

Gold and silver metallic nanoplatforms are the most commonly used as a metallic surface due to their high stabilization and unexpected size-related magnetic and electronic properties. The group of Penadés first presented gold glyconanoparticles in 2001. ${ }^{41}$ The thiol-ended disaccharide lactose (Gal $\beta 1-4 \mathrm{Glc} \beta 1)$ or the trisaccharide Lewis X (Gal $\beta 1-4$ [Fuc $\alpha 1-2]$ GlcNAc $\beta 1, \mathrm{Le}^{\mathrm{X}}$ ) were immobilized on gold nanoparticle surfaces in the presence of the reducing agent $\left(\mathrm{NaBH}_{4}\right)$. In another work, a simple and versatile approach succeeded in preparing gold glyconanoparticles by reducing a gold salt $\left(\mathrm{HAuCl}_{4}\right)$ in the presence of an excess of thiol-armed glycoconjugates. $^{42}$ Basically, there are two synthetic approaches to prepare metallic core GPNs. The first is the direct (one-step) preparation in which gold/silver salts $\left(\mathrm{AuCl}_{4}{ }^{-} / \mathrm{Ag}^{+}\right)$are reduced with $\mathrm{NaBH}_{4}$ in the presence of the desired thiol-functionalized glycopolymers or gold/silver surfaces are introduced by noncovalent interaction. ${ }^{43,44}$ The second approach is the multi-step (generally three steps) procedure in which suitable carbohydrate derivatives are conjugated to previously prepared nanoparticles. ${ }^{45}$

Biotinylated gold GPNs were prepared from well-defined biotinylated glycopolymers, poly( $N$-isopropylacrylamide), poly (ethyleneglycol), and $\mathrm{HAuCl}_{4}$ via the in situ photochemical reduction of $\mathrm{HAuCl}_{4}$ and glycopolymers in the presence of Irgagure-2959, a water-soluble benzoin. These biotinylated gold GPNs with a high colloidal stability showed high affinity for bioconjugation to streptavidin ${ }^{46,47}$ (Fig. 4).

Multivalent manno-glyconanoparticles succeeded in inhibiting DC-SIGN-mediated HIV trans-infection of human activated peripheral blood mononuclear cells. ${ }^{48}$ These mannoGNPs showed the ability to intervene in in vitro HIV direct infection of T-lymphocytes in the nanomolar range. Gibson et al. developed a versatile method to produce silver GPNs by reducing glycopolymers to the thiol-terminal and then grafting them onto the citrate-stabilized AuNPs surface. ${ }^{49}$

Chen and co-workers have recently been able to prepare glycopolymer-functionalized Ag nanoclusters that showed fluorescent and cytotoxicity ability. ${ }^{50}$ The synthesis of sugar- and acid-containing polymers was carried out via RAFT polymerization. Then, these glycopolymers were mixed with $\mathrm{AgNO}_{3}$ and then placed into the CEM instruments. After microwave irradiation treatment, silver nanocluster decorated glycopolymers were fabricated without using reducing agents. Silver nanoclusters were chosen to decorate the glycopolymers due to their fluorescent and cytotoxic properties providing advantages in both cancer imaging and therapy. These nanoclusters showed significant binding ability and cytotoxicity against GLUT over-expressing cancer cells K562. Furthermore, they inhibited their viability possibly through the enhancement of reactive oxygen species (ROS) production.

Recently, the $\mathrm{Cu}(0)$-catalyzed one-pot reaction for the synthesis of glycopolymers was developed to prepare gold GNPs for the first time. ${ }^{51}$ The end-group reduction was performed to make the glycopolymers become grafted to gold nanorods. Lastly, these thiol-terminated glycopolymers covered the surface of gold nanorods to form a self-assembled monolayer on the GNPs surface due to the interaction of the Au-S bond. The obtained glyco-nanorods were examined via Transmission Electron Microscopy (TEM) and DLS. These glycopolymer substituted gold nanoparticles showed a great binding affinity with PNA due to the sufficient numbers of galactose groups on the surface of the nanoparticles (Fig. 5).

\subsection{Quantum dots and magnetic glyconanoparticles}

Fluorescent semiconductor nanocrystals that are termed quantum dots (QDs) have attracted great interest in the last decade due to their unique size-dependent optical properties.
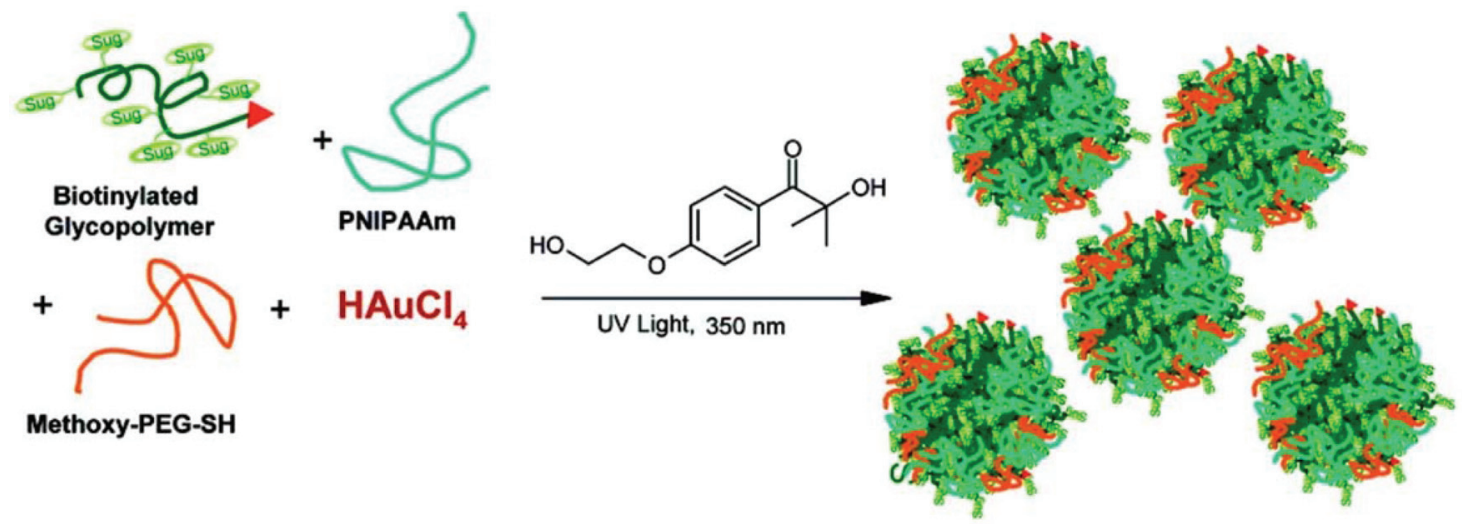

Fig. 4 Schematic representation of the preparation of Au-GPNs via a photochemical process. Reproduced with permission from American Chemical Society, Copyright 2007. ${ }^{47}$ 


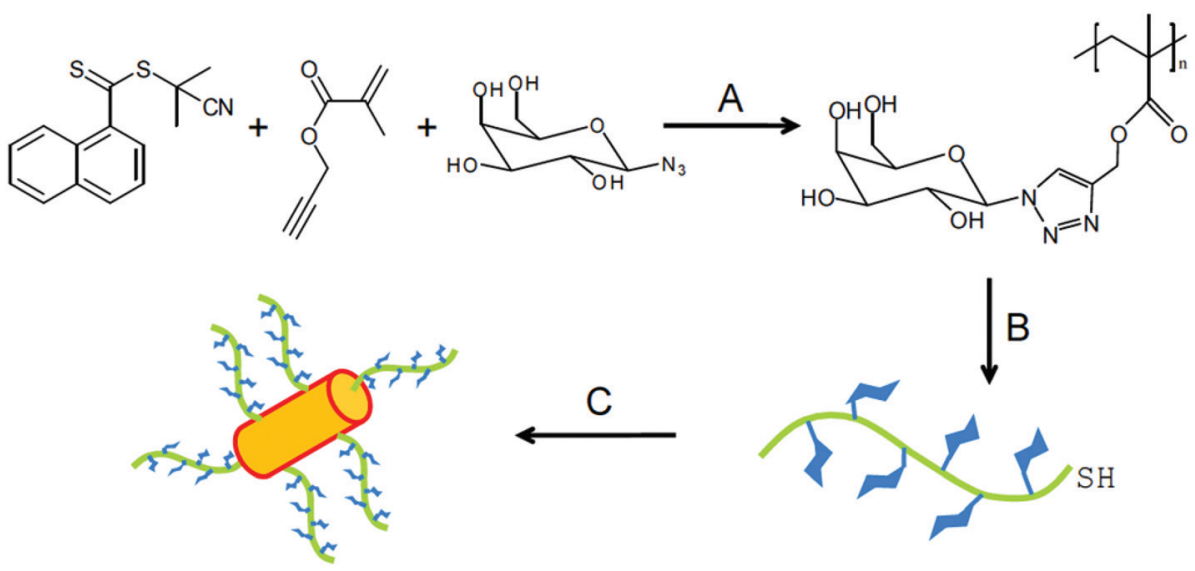

Fig. 5 Synthesis of polymer-coated gold nanoparticle. Conditions: (A) copper powder, methyl 2-bromopropionate, DMSO, $25^{\circ} \mathrm{C}$; (B) 2 equiv. of $\mathrm{R}-\mathrm{NH}_{2} / \mathrm{NEt}_{3}, \mathrm{DMF}, 50^{\circ} \mathrm{C}, 24 \mathrm{~h}$; (C) gold nanorods, $\mathrm{H}_{2} \mathrm{O}, 12 \mathrm{~h}$. Reproduced with permission from Polymer Chemistry, Copyright $2014 .^{51}$

The quantum mechanical and electronic properties of these materials show significant differences from those of the bulk solid. Even though GNPs that contain semiconductor nanocrystals can be used in optical imaging, the initial hydrophobic QDs showed poor solubility in the biological system and high cytotoxicity. Therefore, the protection process should be performed to conjugate with proteins, antibodies, DNA and other small ligands to confer stability and water solubility. QDs capped with sugars (glyco-QDs) have been used for labelling cells and optical imaging in vivo at the same time. The first study was undertaken by Fang and co-workers using glyco-QDs as in vitro bio-labels. ${ }^{52}$ The optical properties of mannoseencapsulated CdSe/ZnS core/shell QDs were determined using confocal microscope imaging to stain living cells. According to the results, despite spreading mannose-QDs over the whole sperm body, GlcNAc-QDs were concentrated at the sperm heads due to the different distribution of the GlcNAc and Man receptors on the sperm surface. In another work, chitosan-QD (CS-QD) hybrid nanospheres were used for bioimaging and biolabeling. ${ }^{53}$ The hybrid nanospheres were prepared by a non-solvent-aided counterion complexation method, in which the as-prepared QDs were added to the CS aqueous solution and crosslinked by the addition of glutaraldehyde aqueous solution. Both studies revealed that QD suitable systems can show strong fluorescence emission and long stability in comparison with classical organic fluorescent dyes for imaging applications.

The coupling of commercially available QD-streptavidin with a biotin end-terminated lactose glycopolymer was reported by Chaikof et al. ${ }^{54}$ Confocal microscopy confirmed fluorescent staining of Ricinus communis agglutinin $\left(\mathrm{RCA}_{120}\right)$ immobilized agarose beads due to the glycopolymer-lectin interaction. Chen and collaborators demonstrated a strategy that directly functionalized ZnS and ZnS:Mn ${ }^{2+}$ QDs with chitosan (CS-ZnS and CS-ZnS:Mn ${ }^{2+}$ QDs). The chitosan functionalized QDs with a mean size of $4.5 \mathrm{~nm}$ were obtained when a mixture of chitosan, $\mathrm{Zn}(\mathrm{Ac})_{2}, \mathrm{Mn}(\mathrm{Ac})_{2}$, and $\mathrm{Na}_{2} \mathrm{~S}_{2} \mathrm{O}_{3}$ aqueous solution was irradiated with a $1.1 \times 10^{15} \mathrm{~Bq}{ }^{60} \mathrm{Co} \gamma$-ray source at room temperature and atmospheric pressure. ${ }^{55}$

Surolia et al. succeeded in demonstrating that melibioseQDs selectively bound to soybean agglutinin (SBA) and were specifically deagglutinated using $\alpha$-galactose. ${ }^{56}$ Moreover, the binding ability of maltotriose-QDs with Con A was analysed via monitoring light scattered at $600 \mathrm{~nm}$ (Fig. 6).

The results confirmed the specific and multivalent carbohydrate-protein interaction. Recently, a biotinylated glycopolymer was functionalized with QDs by coupling RAFT synthesized biotinyl-glycopolymer to QD-COOH in the presence of 1-ethyl-3-[3-dimethylaminopropyl] carbodiimide hydrochloride. These glyco-QDs can be used as suitable fluorescent probes in biological systems due to their easy aqueous dispersion and potential low cytotoxicity. ${ }^{57}$

Magnetic nanoparticles (MNPs) that can be manipulated by an external magnetic field offer new opportunities including the improvement of the quality of magnetic resonance imaging (MRI), hyperthermic treatment for malignant cells, site-specific drug delivery and also for the recent research interest in manipulating cell membranes. Moreover, they have a potential to be used in clinical diagnosis and therapies due to their unique physical properties. Magnetic cores (such as iron oxide, manganese, nickel, and cobalt ferrites) can be functionalised with suitable glycoconjugates. In general, the most commonly used methods of preparing magnetic nanoparticles are co-precipitation, thermal decomposition, and microemulsion. van Kasteren and co-workers used cross-linked iron oxide (CLIO) amine-functionalized dextran-coated nanoparticles as a platform for the incorporation of multiple copies of sialyl Lewis ${ }^{\mathrm{X}}{ }^{58}$ Metal oxide surfaces can be easily modified using alkoxy-, chloro-, aminoalkyl-silanes for further coupling of biomolecules. For example, silica-coated magnetite nanoparticles functionalized with $\alpha$-D-mannosides were achieved through a triazole (Huisgen-type reaction) or an amide (peptidic coupling) linkage. Terminal alkynyl or carboxy functional groups were introduced onto silica oxide-coated magnetite and 


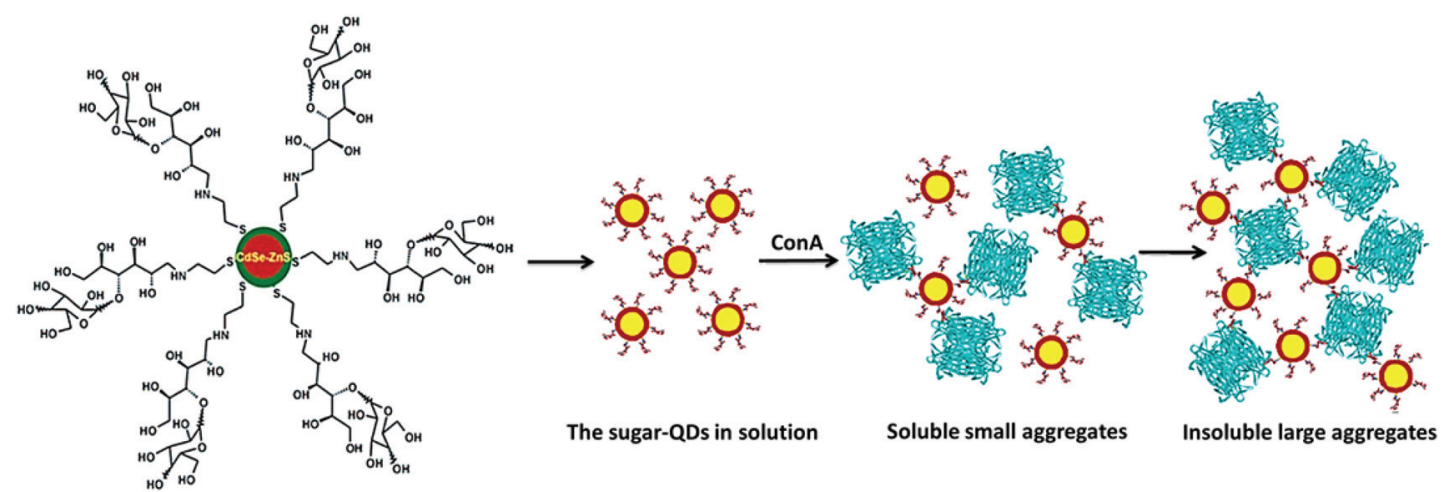

Fig. 6 Schematic representation of agglutination of the sugar-QDs by the Con A tetramer. Reproduced with permission from American Chemical Society, Copyright $2007 .{ }^{56}$

azidopropyl- or aminopropyl-armed $\alpha$-D-mannosides were used to uniformly orientate the carbohydrates at nanoparticles' surface. The binding efficiency with mannose-MGNPs was higher in comparison with other magnetic particles functionalized with lectins. ${ }^{59}$

Recently, Pieters et al. determined from their investigation that the magnetic nanoparticles conjugated to monovalent galabiose conjugates and tetravalent galabiose-linked dendrimers via biotin-streptavidin coupling could be used in detecting Streptococcus suis. ${ }^{60}$ The amount of bacteria was determined by a standard luminescence-based adenosine triphosphate detection assay after magnetic separation. According to these results, the magnetic particles functionalized with monovalent galabiose conjugates showed a higher interaction than the tetravalent ones. The group of Davis used iron oxide nanoparticles (IONPs) to functionalize three different glycopolymers ( $\alpha$-D-mannose, $\alpha$-D-glucose and $\beta$-D-glucose bearing glycopolymers) via grafting to IONPs. ${ }^{61}$
In another work, photochemically-induced coupling of unmodified monosaccharides onto activated spherical magnetite and spindle-type hematite nanoparticles has been performed. ${ }^{62}$ First, 4-azido-2,3,5,6-tetrafluorobenzamido derivatives functionalized the iron oxide nanoparticles by sonication and terminal phosphate groups were coupled to the metal oxide surface of nanoparticles creating $\mathrm{Fe}-\mathrm{O}-\mathrm{P}$ structures. Then, D-mannose was coupled to these functionalized nanoparticles by photochemically-induced $\mathrm{CH}$ without chemical derivatization of the carbohydrates (Fig. 7). These synthesised mannose conjugated magnetic nanoparticles showed high recognition ability towards Con A.

Recently, a novel strategy was developed to produce glycopolymer modified magnetic nanoparticles by the combination of a polymer "grafting from" approach with glycosylation by click chemistry. ${ }^{63,64}$ Poly( $N$-carboxyanhydrides) was synthesised in the presence of 3-aminopropyl-triethoxysilane (APTS)-functionalized magnetic nanoparticles via ring-opening polymerization

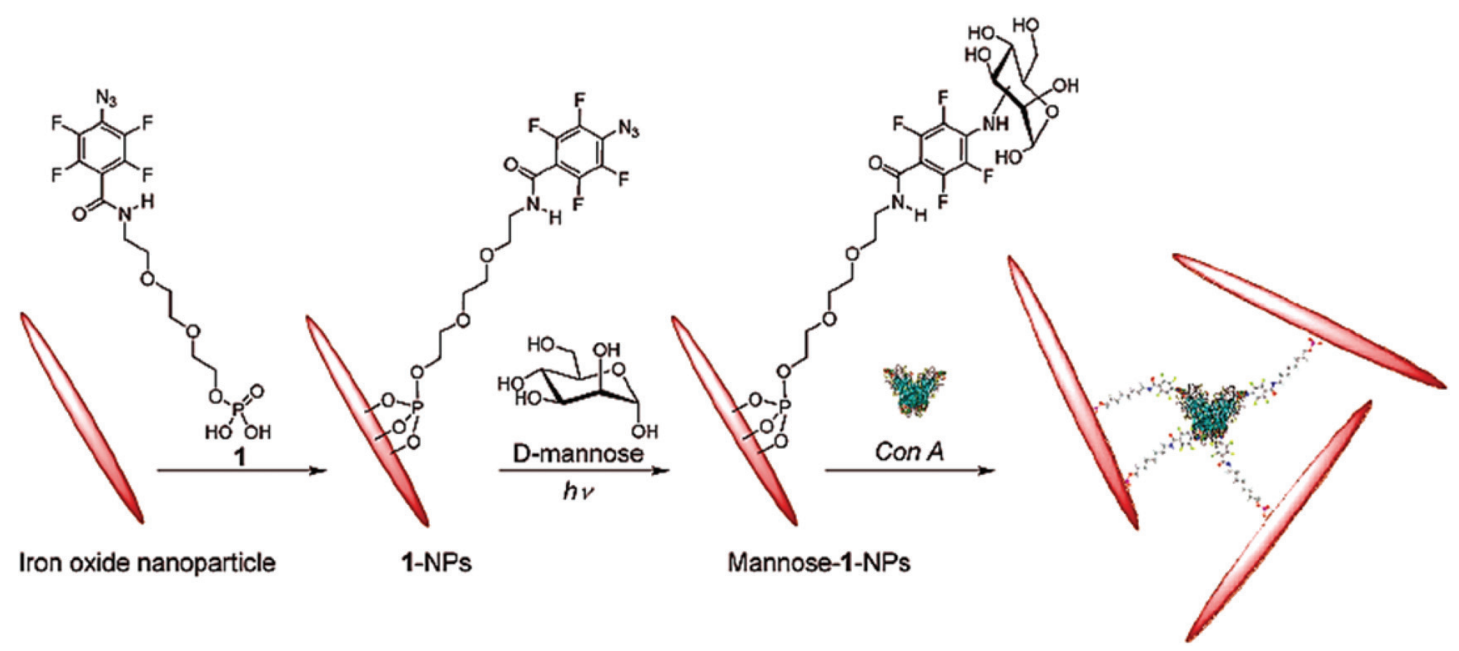

Fig. 7 Functionalization of hematite nanoparticles with 1 followed by coupling of D-mannose and subsequent binding with Con A. Reproduced with permission from American Chemical Society, Copyright $2009 .{ }^{62}$ 
and afforded clickable alkyne groups. The azide-functionalized galactose was then attached on these nanoparticles to fabricate glycol-MNPs by the Huisgen click reaction. Such particles exhibited excellent water dispersion properties, optimal $T_{1^{-}}$ weighting and selective binding to lectins.

\subsection{Polymeric glyconanoparticles}

A wide range of polymeric glyconanoparticles that were prepared in the last few years have exhibited excellent and significant recognition properties towards lectins. Very recent and elegant synthetic routes have allowed polymer chemists to prepare polymeric glyconanoparticles with different chemical functional groups and a broad variety of morphologies. These polymeric glyconanoparticles are promising in the creation of different bioactive glycopolymer structures for various health related applications such as drug delivery, biomaterials, bioand nanotechnologies, and gene therapy. Chen et al. developed a strategy to synthesise self-assembled porphyrin-glycopolymer conjugates via the combination of RAFT polymerization and one-pot conjugation reaction as a one-pot of multi-reactions. ${ }^{65}$ These porphyrin-PMAG conjugates showed self-assembly behaviour to form micelles in the water due to hydrophobic porphyrin in the middle and hydrophilic glycopolymer at both ends. The binding ability of the synthesised glyconanoparticles was tested with Con A and showed an anticancer effect for cancer cells (K562). They showed a high and specific binding ability with Con A. Moreover, in in vitro studies, the cytotoxic test of the glycomicelles against $\mathrm{K} 562$ cells in the dose revealed that these self-assembled micelles killed these cancer cells under light irradiation and in a light treatment length dependent manner. Therefore, this report is very important for the development of applications for cancer imaging and therapy ${ }^{65}$ (Fig. 8).

The synthesis of cationic poly(methacrylamidotrehalose) (poly(trehalose)) was reported by Reineke et al. via RAFT polymerization. ${ }^{66}$ Nanocomplexes of these cationic polymers with siRNA were fabricated in order to develop the delivery system of the targeting system to glioblastoma cells. Another versatile strategy to synthesize glycopolymers through condensation polymerization of esterified carbohydrates and diamines has also been reported by the same group. These glycopolymers formed a nanocomplex with nucleic acid and were used for the purpose of gene delivery. ${ }^{67,68}$ Zhou and collaborators investigated a strategy for gene delivery system based on the synthesis of glycopolymers grafted onto poly( $\mathrm{L}^{-}$ lysine) (PLL). ${ }^{69}$ Despite the significant condensation capacity with plasmid DNA due to the positively charged hydrophilic amino group in water, PLL is not generally chosen as a gene delivery vector because of high cytotoxicity and low transfection efficiency. However, herein, PLL was modified by welldefined saccharide-containing polymers in order to reduce the cytotoxicity and increase the transfection efficiency of PLL. The glycopolymer modified PLL showed lower cytotoxicity than PLL according to the MTT assays with the mouse embryonic fibroblast cell line (NIH3T3) and human hepatoma cell line (HepG2). The pDNA condensation of the glycopolymer modified PLL complexes was investigated by agarose gel electrophoresis. The results showed that a low SD (substitution degree) on PLL increased the pDNA condensation capacity. This work allowed PLL to be more useful and applicable for gene delivery with enhanced biological properties.
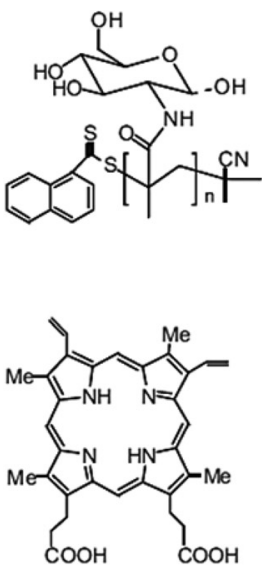

(1)

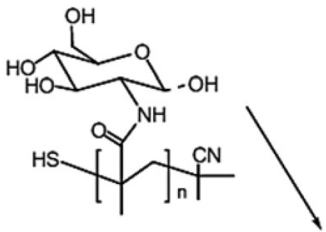

$+$

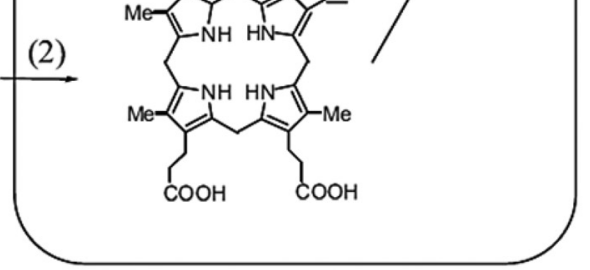

One-pot conjugation
(3)

(4)

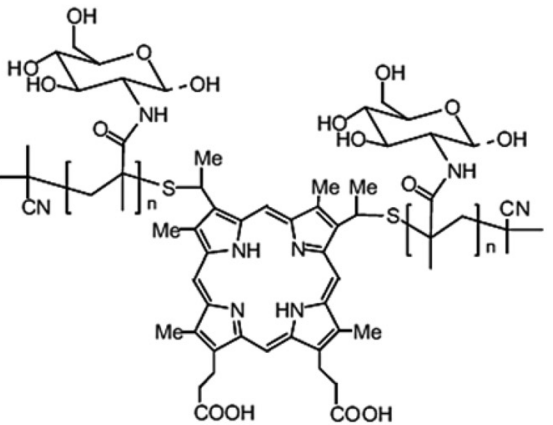

Fig. 8 Schematic representation of one-pot synthesis of glycopolymer-porphyrin conjugate: (1) reduction of RAFT end group to thiols, (2) reduction of $\mathrm{PpIX}$ to protoporphyrinogen, (3) thiol-ene reaction of protoporphyrinogen with thiol-terminal glycopolymer and (4) the oxidation of protoporphyrinogen to afford the porphyrin-glycopolymer conjugate. Reproduced with permission from Macromolecular Bioscience, Copyright $2012 .^{65}$ 
Chen and co-workers have performed three self-assembled nanoparticles from triblock copolymers with the same polymeric backbone but different sugar regioisomers as pendant groups. $^{70}$ First, a rod-block of the poly(9,9-dioctylfluorene) macroinitiator was conjugated with the bromine-functionalized polyfluorene (PF) initiator from its two ends to exist in the middle block of the glycopolymers. The triblock copolymer (PGMA- $b$-PF- $b$-PGMA) was synthesised and reacted with $\mathrm{NaN}_{3}$ for the sugars modified with alkynes click targeting. 1-(2'Propargyl)-D-galactose $(\alpha: \beta=10: 3)$ and 1-(2'-propargyl)-Dmannose were prepared and used for the click chemistry that gave PF-1-Gal, PF-6-Gal and PF-1-Man (Fig. 9). Well-dispersed spheres were obtained from the polymer self-assembled into nanoparticles with the glyco block as the shell and the rod block as the core. The bioactivity of these formed nano-objects was analysed with PNA and Erythrina cristagalli agglutinin (ECA) via a quartz crystal microbalance (QCM).

Thermoresponsive micelles were prepared from 'coilcomb-coil' triblock self-assembly glycopolymers. ${ }^{71}$ These triblock glycopolymers were synthesized via the combination of RAFT and ring-opening polymerization. The triblock glycopolymers were grafted with $\varepsilon$-caprolactone at the middle block (HEMA section) to yield poly(3-O-methacryloyl-1,2:5,6-di-O-isopropylidene-D-glucofuranose)-block-poly(2-hydroxyethyl methacrylate-graft-poly( $\varepsilon$-caprolactone $)$ )-block-poly( $N$-isopropylacrylamide) (PMAIpGlc- $b$-P(HEMA-g-PCL)- $b$-PNIPAM). Another elegant method was developed to synthesize the thermoresponsive glycopolymers poly( $\mathrm{N}$-isopropylacrylamide-co-6-Ovinyladipoyl-D-glucose) (poly-NIPAM-co-OVDG; PND) and poly( $\mathrm{N}$-isopropylacrylamide-co-6-O-vinylazelaicoyl-D-glucose) (polyNIPAM-co-OVZG; PNZ) via a free radical polymerization process. ${ }^{72}$ An electrospinning process was employed to prepare nanofibers comprising blends of poly-NIPAM-co-OVDG/polyNIPAM-co-OVZG with poly-L-lactide-co-e-caprolactone (PLCL). An electrical potential of $12 \mathrm{kV}$ was applied while the spinning solution was flowing through a stainless steel capillary needle to a collector plate coated with Al foil. The obtained nanofibers were characterized by using Scanning Electron Microscopy (SEM). Additionally, an MTT assay confirmed that these nanofibers have generally good biocompatibility with HeLa cells and minimum cytotoxicity as well. Even though these nanofibers did not have sufficient ability to inhibit non-specific adsorption of bovine serum albumin onto their surfaces, they showed significant interaction with Con A. They can be utilized easily in other glycosylated polymers given their temperature sensitive properties and the sensitive and specific recognition with lectins.

The glycosylated peptide-based block copolymer was synthesised via the ring-opening polymerization of $N$-carboxyanhydrides to form different well-defined morphologies in aqueous solution. ${ }^{73}$ Recently, Armes and co-workers presented the synthesis of galactose-functionalized diblock copolymer spheres, worm-like micelles and vesicles by the polymeriz-<smiles>[R]OC(=O)C(C)(Br)CC(C)(C)C(=O)Oc1ccc(-c2ccc3c(c2)C(C)(C)c2cc(-c4ccc(OC(=O)C(C)(C)C(C)(C)C(C)(C)C(=O)O[R])cc4)ccc2-3)cc1</smiles>

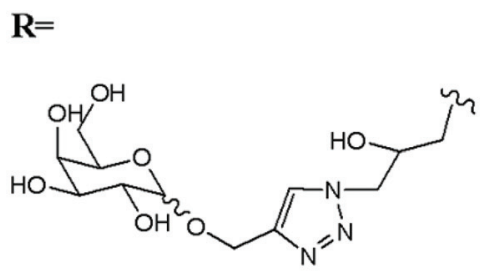

PF-1-Gal

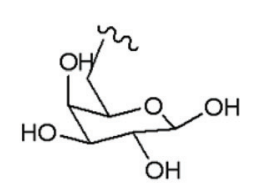

PF-6-Gal

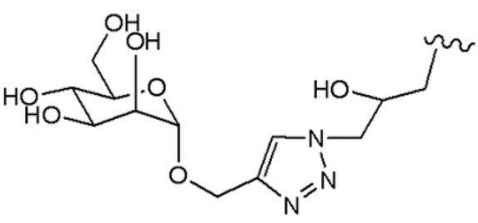

PF-1-Man

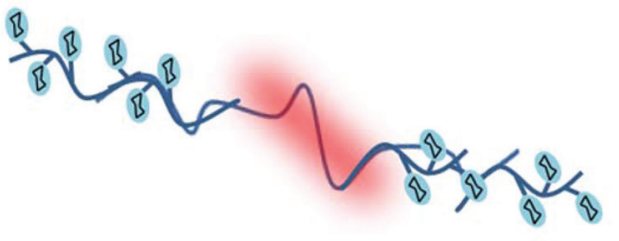

Self-Assembly

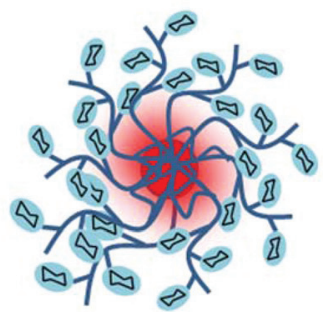

Fig. 9 Chemical structures of PF-1-Gal, PF-6-Gal, and PF-1-Man and schematic representation of the self-assembled nanoparticles. 
ation-induced self-assembly approach in concentrated aqueous solution and exploited the relationship between the interaction of galactose-specific lectins with different morphologies of the nanoparticles ${ }^{74}$ (Fig. 10).

Fernández-García and collaborators reported the preparation of various amphiphilic block glycopolymers based on $2-\{[$ (D-glucosamin-2- $N$-yl)carbonyl] oxy\}ethylacrylate (HEAGI) and $n$-butyl acrylate (BA) and methyl methacrylate (MMA) via ATRP. ${ }^{75}$ A small library of the well-defined amphiphilic block glycopolymers having di- and triblock glycopolymers with different hydrophobic blocks and varying hydrophilic block lengths was demonstrated. The self-assembly ability of the obtained amphiphilic block glycopolymers allowed the formation of micelles in aqueous solution. The dynamic light scattering measurements revealed that the average diameter values are between 150 and $160 \mathrm{~nm}$ due to strong hydrogen bond interactions between the hydroxyl groups and these polymers. Unexpectedly, the architecture of the block, diblock, or triblock glycopolymers did not show any significant influence on their interaction with Con A. In another study, the same group have proposed the syntheses of different amphiphilic glycopolymers via free radical polymerization. $^{76}$ Poly(ethylene glycol) methacrylate (PEGMA) was prepared and copolymerised with methyl acrylate (MA). The free radical copolymerization of the glycomonomer and MA was undertaken using AIBN as an initiator in DMSO at $70{ }^{\circ} \mathrm{C}$. The different amphiphilic glycopolymers with the different ratios of the monomers were prepared by using this approach. The binding affinity of these polymer coated particles with Con A was analysed via fluorescence microscopy. It was found that the number of glycounits in the glycopolymer stabilizers affected the binding ability directly and significantly. The synthesis of biodegradable polycarbonate displaying either glucose or galactose surface moieties was performed via controlled ring-opening polymerization to fabricate micelles in aqueous media. ${ }^{77}$

\section{Conclusion and future perspective}

The integration of nanotechnology with carbohydrate-based systems has opened a new avenue for creating more complex scaffolds that exhibit excellent and significant recognition properties towards lectins. Very recent and elegant synthetic routes have allowed scientists to prepare a wide range of glyconanomaterials with different biofunctionalities. The conjugation of sugar derivatives onto metallic nanoplatforms presents interesting properties which include a wide array of assembling models and size-related electronic, magnetic and optical properties. They are good biomimetic models of carbohydrate presentation at the cell surface. Glyco-quantum dots have attracted increasing attention due to their use as biological markers. Magnetic GNPs offer new opportunities including the improvement of the quality of MRI, hyperthermic treatment of malignant cells, site-specific drug delivery and also clinical diagnosis and therapies due to their unique physical properties. All these studies showed that multivalent lectincarbohydrate interactions can be succeeded by the integration of biologically significant carbohydrates into nanosystems to develop versatile functions and medical or pharmaceutical applications. Moreover, these GPNs can mimic the behavior of naturally existing glycocalyx.

The recent developments in carbohydrate-based nanomaterials have allowed the preparation of the broad diversity of glyconanoparticles that present outstanding physical, chemical and biological properties to improve their utility in biomedicine and materials science. It is now possible to insert different types of glycans into nanosystems due to enhancement of multifunctionality. QDs can be used as a model system in biosensor applications due to their relatively small size and versatile surface chemistry functionalization, which make them useful for designing and engineering nanocarrier platforms. ${ }^{78,79}$ Multivalent glycopolymer-stabilized AuNPs that offer use as a potential synthetic cancer vaccine generate a significant immune response upon binding to mucin-1 glycoproteins expressed on breast cancer cell lines. ${ }^{80}$ The broad diversity of polymeric nanoparticles has been developed for their targeted delivery efficacies as non-viral vectors for gene and drug delivery applications. ${ }^{81-83}$

Even though considerable work has been done so far, there are still some questions that are waiting to be answered regarding the investigation of carbohydrate-based interactions. 
However, the limitations in the preparation of glyconanoparticles are still the major challenge. When the control of glyconanoparticle composition using different carbohydrate and noncarbohydrate ligands is achieved with extreme precision, it will open new avenues for the development of precision glyconanoparticles for in vitro and in vivo applications in the next few decades.

\section{Acknowledgements}

The authors are thankful for the funding provided by the Turkish Land Forces and EU Horizon2020 Innovative Training Network Programme, EURO-SEQUENCES no. 642083.

\section{References}

1 M. Marradi, F. Chiodo, I. Garcia and S. Penades, Chem. Soc. Rev., 2013, 42, 4728-4745.

2 N. Kottari, Y. Chabre, R. Sharma and R. Roy, in Multifaceted Development and Application of Biopolymers for Biology, Biomedicine and Nanotechnology, ed. P. K. Dutta and J. Dutta, Springer, Berlin, Heidelberg, 2013, vol. 254, pp. 297-341.

3 C. Fasting, C. A. Schalley, M. Weber, O. Seitz, S. Hecht, B. Koksch, J. Dernedde, C. Graf, E.-W. Knapp and R. Haag, Angew. Chem., Int. Ed., 2012, 51, 10472-10498.

4 R. Ribeiro-Viana, M. Sánchez-Navarro, J. Luczkowiak, J. R. Koeppe, R. Delgado, J. Rojo and B. G. Davis, Nat. Commun., 2012, 3, 1303.

5 S.-J. Richards, M. W. Jones, M. Hunaban, D. M. Haddleton and M. I. Gibson, Angew. Chem., Int. Ed., 2012, 51, 78127816.

6 J. Luczkowiak, A. Muñoz, M. Sánchez-Navarro, R. RibeiroViana, A. Ginieis, B. M. Illescas, N. Martín, R. Delgado and J. Rojo, Biomacromolecules, 2013, 14, 431-437.

7 The Sugar Code, ed. H.-J. Gabius, Wiley-Blackwell, Weinheim, Germany, 2010, ISBN: 978-3-527-32089-9.

8 D. P. Gamblin, E. M. Scanlan and B. G. Davis, Chem. Rev., 2009, 109, 131.

9 S. K. Podder, A. Surolia and B. K. Bachhawat, Eur. J. Biochem., 1974, 44, 151-160.

10 C. R. Becer, Macromol. Rapid Commun., 2012, 33, 742-752.

11 K. Matsuura, M. Hibino, T. Ikeda, Y. Yamada and K. Kobayashi, Chem. - Eur. J., 2004, 10, 352-359.

12 Q. Zhang, L. Su, J. Collins, G. Chen, R. Wallis, D. Mitchell, D. M. Haddleton and C. R. Becer, J. Am. Chem. Soc., 2014, 136, 4325-4332.

13 S. Slavin, J. Burns, D. M. Haddleton and C. R. Becer, Eur. Polym. J., 2011, 47, 435-446.

14 K. Babiuch, R. Wyrwa, K. Wagner, T. Seemann, S. Hoeppener, C. R. Becer, R. Linke, M. Gottschaldt, J. r. Weisser, M. Schnabelrauch and U. S. Schubert, Biomacromolecules, 2011, 12, 681-691.

15 L. L. Kiessling, J. E. Gestwicki and L. E. Strong, Angew. Chem., Int. Ed., 2006, 45, 2348-2368.
16 H.-J. Gabius, H.-C. Siebert, S. André, J. Jiménez-Barbero and H. Rüdiger, ChemBioChem, 2004, 5, 740.

17 I. Kurtulus, G. Yilmaz, M. Ucuncu, M. Emrullahoglu, C. R. Becer and V. Bulmus, Polym. Chem., 2014, 5, 15931604.

18 M. Semsarilar, V. Ladmiral and S. Perrier, Macromolecules, 2010, 43, 1438-1443.

19 Y. Gou, S. Slavin, L. Voorhaar, D. M. Haddleton and C. R. Becer, ACS Macro Lett., 2012, 1, 180-183.

20 G. Yilmaz and C. R. Becer, Front. Bioeng. Biotechnol., 2014, 2,39 .

21 S. Thobhani, B. Ember, A. Siriwardena and G.-J. Boons, J. Am. Chem. Soc., 2003, 125, 7154-7155.

22 N. Sharon and H. Lis, Glycobiology, 2004, 14, 53R.

23 N. Sharon and H. Lis, Science, 1989, 246, 227-234.

24 G. Ashwell and J. Harford, Annu. Rev. Biochem., 1982, 51, 531.

25 C. R. Becer and L. Hartmann, Glycopolymer Code, RSC Polymer Chemistry Series, 2015, ISBN: 978-1-84973-978-8.

26 O. Sperling, A. fuchs and T. K. Lindhorst, Org. Biomol. Chem., 2006, 4, 3913-3922.

27 N. Sharon, Trends Biochem. Sci., 1993, 18, 221-226.

28 R. J. Pieters, Org. Biomol. Chem., 2009, 7, 2013-2025.

29 R. A. Newman, G. Uhlenbruck, K. Schumacher, A. V. Mil and D. Karduck, Z. Immunitatsforschung-Immunobiol., 1978, 15, 451.

30 W. J. Peumans, H. M. Stinissen and A. R. Carlier, Arch. Int. Physiol., Biochim. Biophys., 1982, 90, B60.

31 Y. Endo, K. Mitsui, M. Motizuki and K. Tsurugi, J. Biol. Chem., 1987, 262, 5908.

32 M. H. Stenzel, Polym. Chem., 2011, 2, 1879.

33 D. C. Kilpatrick, Biochim. Biophys. Acta, Gen. Subj., 2002, 1572, 187-197.

34 J. M. Berg, J. L. Tymoczko and L. Stryer, Biochemistry, 5th edn, 2002, ISBN-10: 0-7167-3051-0.

35 P. R. Taylor, L. Martinez-Pomares, M. Stacey, H. H. Lin, G. D. Brown and S. Gordon, Annu. Rev. Immunol., 2005, 23, 901-944.

36 A. Varki, R. D. Cummings and J. D. Esko, et al., Essentials of Glycobiology, 2nd edn, 2009, ISBN-13: 9780879697709.

37 N. M. Dahms and M. K. Hancock, Biochim. Biophys. Acta, Gen. Subj., 2002, 1572(2), 340.

38 A. Agrawal, P. P. Singh, B. Bottazzi, C. Garlanda and A. Mantovani, Adv. Exp. Med. Biol., 2009, 653, 98-116.

39 A. Mantovani, C. Garlanda, A. Doni and B. Bottazzi, J. Clin. Immunol., 2008, 28(1), 13.

40 R. T. Lee and Y. C. Lee, Glycoconjugate J., 2000, 17, 543551.

41 J. M. de la Fuente, A. G. Barrientos, T. C. Rojas, J. Rojo, J. Cañada, A. Fernández and S. Penadés, Angew. Chem., Int. Ed., 2001, 40, 2257-2261.

42 A. G. Barrientos, J. M. Fuente, T. C. Rojas, A. Fernandez and S. Penades, Chem. - Eur. J., 2003, 9, 1921.

43 A. L. Parry, N. A. Clemson, J. Ellis, S. S. Bernhard, B. G. Davis and N. R. Cameron, J. Am. Chem. Soc., 2013, 135, 9362-9365. 
44 R. Narain, A. Housni, G. Gody, P. Boullanger, M.-T. Charreyre and T. Delair, Langmuir, 2007, 23, 1283512841.

45 M. Takara, M. Toyoshima, H. Seto, Y. Hoshino and Y. Miura, Polym. Chem., 2014, 5, 931-939.

46 R. Narain, A. Housni, G. Gody, P. Boullanger, M.-T. Charreyre and T. Delair, Langmuir, 2007, 23, 1283512841.

47 F. B. Lollmahomed and R. Narain, Langmuir, 2011, 27, 12642-12649.

48 O. Martínez-Ávila, L. M. Bedoya, M. Marradi, C. Clavel, J. Alcamí and S. Penadés, ChemBioChem, 2009, 10, 1806.

49 J. Lu, W. Zhang, S.-J. Richards, M. I. Gibson and G. Chen, Polym. Chem., 2014, 5, 2326-2332.

50 W. Lu, W. Ma, J. Lu, X. Li, Y. Zhao and G. Chen, Macromol. Rapid Commun., 2014, 35, 827.

51 J. Lu, W. Zhang, S.-J. Richards, M. I. Gibson and G. Chen, Polym. Chem., 2014, 5, 2326.

52 A. Robinson, J. M. Fang, P. T. Chou, K. W. Liao, R. M. Chu and S. J. Lee, ChemBioChem, 2005, 6, 1905.

53 Y. Lin, L. Zhang, W. Yao, H. Qian, D. Ding, W. Wu and X. Jiang, ACS Appl. Mater. Interfaces, 2011, 3, 995-1002.

54 X.-L. Sun, W. Cui, C. Haller and E. L. Chaikof, ChemBioChem, 2004, 5, 1596.

55 S. Chang, B. Kang, Y.-d. Dai, H.-x. Zhang and D. Chen, Nanoscale Res. Lett., 2011, 6, 591.

56 P. Babu, S. Sinha and A. Surolia, Bioconjugate Chem., 2007, 18, 151.

57 X. Jiang, M. Ahmed, Z. Deng and R. Narain, Bioconjugate Chem., 2009, 20, 994-1001.

58 S. I. van Kasteren, S. J. Campbell, S. Serres, D. C. Anthony, N. R. Sibson and B. G. Davis, Proc. Natl. Acad. Sci. U. S. A., 2009, 106, 18-23.

59 K. El-Boubbou, C. Grunden and X. Huang, J. Am. Chem. Soc., 2007, 129, 13393.

60 N. Parera Pera, A. Kouki, S. Haataja, H. M. Branderhorst, R. M. J. Liskamp, G. M. Visser, J. Finne and R. J. Pieters, Org. Biomol. Chem., 2010, 8, 2429.

61 J. S. Basuki, L. Esser, H. T. T. Duong, Q. Zhang, P. Wilson, M. R. Whittaker, D. M. Haddleton, C. Boyer and T. P. Davis, Chem. Sci., 2014, 5, 715-726.

62 L. H. Liu, H. Dietsch, P. Schurtenberger and M. Yan, Bioconjugate Chem., 2009, 20, 1355.

63 T. Borase, T. Ninjbadgar, A. Kapetanakis, S. Roche, R. O'Connor, C. Kerskens, A. Heise and D. F. Brougham, Angew. Chem., Int. Ed., 2013, 52, 3164-3167.
64 T. D. Farr, C.-H. Lai, D. Grünstein, G. Orts-Gil, C.-C. Wang, P. Boehm-Sturm, P. H. Seeberger and C. Harms, Nano Lett., 2014, 14, 2134.

65 W. Lu, W. Ma, J. Lu, X. Li, Y. Zhao and G. Chen, Macromol. Rapid Commun., 2014, 35, 827.

66 A. Sizovs, L. Xue, Z. P. Tolstyka, N. P. Ingle, Y. Wu, M. Cortez and T. M. Reineke, J. Am. Chem. Soc., 2013, 135, 15417-15424.

67 V. P. Taori, H. Lu and T. M. Reineke, Biomacromolecules, 2011, 12, 2055-2063.

68 M. Tranter, Y. Liu, S. He, J. Gulick, X. Ren, J. Robbins, W. K. Jones and T. M. Reineke, Mol. Ther., 2012, 20, 601608.

69 D. Zhou, C. Li, Y. Hu, H. Zhou, J. Chen, Z. Zhang and T. Guo, Int. J. Biol. Macromol., 2012, 50, 965.

70 P. Sun, Y. He, M. Lin, Y. Zhao, Y. Ding, G. Chen and M. Jiang, ACS Macro Lett., 2013, 3, 96.

71 Y. Luo, L. Liu, X. B. Wang, H. T. Shi, W. H. Lv and J. Y. Li, Soft Matter, 2012, 8, 1634-1642.

72 M. Kamigaito, T. Ando and M. Sawamoto, Chem. Rev., 2001, 101, 3689.

73 J. Huang, C. Bonduelle, J. Thévenot, S. Lecommandoux and A. Heise, J. Am. Chem. Soc., 2011, 134, 119-122.

74 V. Ladmiral, M. Semsarilar, I. Canton and S. P. Armes, J. Am. Chem. Soc., 2013, 135, 13574-13581.

75 A. Muñoz-Bonilla, O. León, V. Bordegé, M. Sánchez-Chaves and M. Fernández-García, J. Polym. Sci., Part A: Polym. Chem., 2013, 51, 1337.

76 M. Alvárez-Paino, R. Juan-Rodríguez, R. Cuervo-Rodríguez, A. Muñoz-Bonilla and M. Fernández-García, J. Colloid Interface Sci., 2014, 417, 336.

77 F. Suriano, R. Pratt, J. P. K. Tan, N. Wiradharma, A. Nelson, Y.-Y. Yang, P. Dubois and J. L. Hedrick, Biomaterials, 2010, 31, 2637-2645.

78 A. P. Alivisatos, Science, 1996, 271, 933-937.

79 C.-Y. Zhang, H.-C. Yeh, M. T. Kuroki and T.-H. Wang, Nat. Mater., 2005, 4, 826-831.

80 A. L. Parry, N. A. Clemson, J. Ellis, S. S. Bernhard, B. G. Davis and N. R. Cameron, J. Am. Chem. Soc., 2013, 135, 9362-9365.

81 M. Ahmed and R. Narain, Biomaterials, 2011, 32, 52795290.

82 O. Onaca, R. Enea, D. W. Hughes and W. Meier, Macromol. Biosci., 2009, 9, 129-139.

83 R. Mo, T. Jiang, R. DiSanto, W. Tai and Z. Gu, Nat. Commun., 2014, 5. 